\title{
Genetic analyses of novel temperament and milkability traits in Norwegian Red cattle based on data from automatic milking systems
}

\author{
K. B. Wethal* and B. Heringstad \\ Department of Animal and Aquacultural Sciences, Norwegian University of Life Sciences, PO Box 5003, 1432 Ås, Norway
}

\begin{abstract}
The number of dairy cows milked in automatic milking systems (AMS) is steadily increasing in Norway. Capacity and efficiency of AMS are highly dependent on the individual cow's milking efficiency, such as milking speed and occupation time in the milking robot. Cows meet new challenges in herds utilizing AMS. Consequently, new or revised traits may be needed for genetic evaluation of dairy cattle. The AMS records relevant information on an individual cow basis. The aims of this study were to estimate genetic parameters of new automatically recorded milkability and temperament traits. Data from 77 commercial herds with Norwegian Red dairy cattle were analyzed by mixed linear animal models. The final data set contained 1,012,912 daily records from 4,883 cows in first to ninth lactation. For variance component estimation, univariate and bivariate models were used. Daily records of box time (BT), average flow rate (FR), kilograms of milk per minute of box time (MEF), handling time (HT), log-transformed HT, milking frequency, and milking interval were analyzed with repeatability models. Among these traits, FR, BT, and MEF showed the highest heritabilities of $0.48,0.27$, and 0.22 , respectively, whereas heritability of log-transformed HT, HT, milking frequency, and milking interval was low (0.02-0.07). Unsuccessful milkings expressed as rejected milkings, incomplete milkings (IM), milkings with kick-offs (KO), and teat not found also showed low heritabilities $(0.002-0.06)$. Due to low frequency, $\mathrm{KO}$, rejected milkings, IM, and teat not found were also analyzed as proportions per lactation, which resulted in slightly higher heritability estimates. Genetic correlations were favorable and intermediate to strong between BT, HT, MEF, and FR with absolute values above 0.50 . Intermediate and favorable correlations were found for IM and KO with BT, HT, MEF,
\end{abstract}

Received March 15, 2019.

Accepted May 3, 2019.

*Corresponding author: karoline.bakke@nmbu.no and FR. Cow milkability in AMS can be improved by selection for reduced number of unsuccessful milkings, faster FR, increased MEF, and shorter BT and HT. Our results confirm that automatically recorded data on milkability and temperament can be valuable sources of information for routine genetic evaluations and that milking efficiency in AMS can be genetically improved.

Key words: milking efficiency, temperament, automatic milking system, genetic parameter

\section{INTRODUCTION}

The number of dairy farms with milking robots or automatic milking systems (AMS) has increased in Norway since the first farm installed an AMS in 2000. The Norwegian dairy association Tine reported that $44 \%$ of milk produced in 2017 came from cows in AMS herds, and by 2018 the proportion was predicted to be more than 50\% (Tine, 2017). Automatic milking systems are believed to be common in Norway due to small average herd size ( $\sim 26$ cows; Tine, 2017$)$ and relatively high labor costs. The proportion of dairy farms with AMS is expected to further increase as the government bans the use of tiestalls beginning in 2034 .

Dairy cows meet new challenges in AMS that may necessitate new traits or revise existing traits in the breeding program. Automatic milking systems generate vast amounts of data with potentially novel phenotypes, and records on, for example, milkability or unsuccessful milkings may be useful for assessing the efficiency of individual cows. The objective information being collected from the AMS shows high repeatability between milkings, ranging from 0.73 to 0.89 for milkability (Gäde et al., 2006; Carlström et al., 2013). Several traits are important for cow efficiency and functionality in AMS, including ability to stay calm during preparation and attachment of milking equipment as well as high yield and milking speed. Uneasy cows that kick off the milking equipment prolong preparation and attachment times. In addition, the cows might have longer occupation time due to kick-offs (KO). There- 
fore, short occupation time and ability to quickly leave the AMS after the last teat cup is removed are desirable traits. All of these traits are important for utilizing AMS efficiently. Thus far, relatively few genetic studies have analyzed different milkability, temperament, and behavioral traits in AMS.

The majority of studies using data from AMS focus on genetic parameters of production traits, milkability, flow rate (FR), and milk quality traits (Gäde et al., 2006; König et al., 2006; Nixon et al., 2009; Byskov et al., 2012; Carlström et al., 2013, 2014). Objective registration of milking traits and time used is accurate and shows genetic variation. In a study by Carlström et al. (2013), average FR ( $\mathrm{kg}$ of milk/min) and occupation time (box time, BT; min) were estimated to have heritabilities from 0.37 to 0.48 and 0.38 to 0.44 , respectively, in first- to third-parity Swedish Red cows. Vosman et al. (2018) and Bakke and Heringstad (2015) estimated heritabilities for milkability (measured as $\mathrm{kg}$ of milk/min of BT) to be around 0.30 .

Some studies investigated the use of AMS records as objective measurements of behavioral traits (Rinell et al., 2014; Carlström et al., 2016; Stephansen et al., 2018). Teat cup KO in AMS were found to be genetically related to cows' milking temperament. Rinell et al. (2014) analyzed 2 differently defined KO traits in Swedish Holstein cows; daily number of milkings with $\mathrm{KO}$ and proportion of $\mathrm{KO}$ during lactation showed heritability of 0.06 and 0.31 , respectively. Carlström et al. (2016) investigated traits related to cow temperament in AMS for Swedish Red dairy cattle. Information about unsuccessful milkings, such as incomplete milking (IM) and teat cup attachment failures (or $\mathrm{KO}$ ), showed low to medium heritabilities of 0.06 and 0.21 , respectively. In the same study, genetic parameters of handling time (HT; defined as time in AMS before and after milking) in minutes were investigated. The estimated heritability for handling time was 0.15 for Swedish Reds and 0.05 for Swedish Holsteins; a strong genetic association between subjectively scored temperament and teat cup $\mathrm{KO}$ in AMS was also found (Carlström et al., 2016). Temperament in Swedish Reds scored subjectively on a 9-point scale showed a genetic correlation of -0.71 with KO traits. Hence, the current subjectively scored temperament describes, to a large degree, the same genetic variation as KO in AMS. Similarly, Bakke and Heringstad (2015) estimated a favorable genetic correlation of 0.54 between temperament scored subjectively on a 3-point scale and proportion of $\mathrm{KO}$ in AMS for Norwegian Red cows. Even though studies have shown a considerable potential of AMS data for genetic evaluation (Carlström et al., 2013, 2014, 2016), studies have yet to define new temperament and milkability traits in
AMS for Norwegian Red cows. The aim of this study was to estimate genetic parameters for traits important for cow milking efficiency in AMS.

\section{MATERIALS AND METHODS}

\section{Description of Data Set}

The data used in the current study were from 77 commercial Norwegian dairy herds with AMS first installed between 2000 and 2015. All farms had a DeLaval (Tumba, Sweden) Voluntary Milking System and were randomly chosen such that they were representative of the robot density in each Norwegian county. DeLaval Norway provided remote access to on-farm computers, and an external connection was set up after permission from each farmer. Data were downloaded between January and July 2017, and the farms had DeLaval DelPro version $3.7,4.5$, or 5.2 software installed. The raw data contained information about each milking and rejected milking (RM) for each cow. Due to local memory limitations, the systems deleted records older than $1 \mathrm{yr}$ on a daily basis. Therefore, only $365 \mathrm{~d}$ with data could be obtained from each herd. The reports contained information on milk yield and milking speed in each udder quarter; date, time, and length of each visit; and problems with the milking session, such as $\mathrm{KO}$ and IM.

\section{Definition of Traits}

Milkability. Box time is the time from when a cow enters the AMS to when it exits the milking unit when milking is finished. Milk yield per time unit (MEF) was defined as the ratio of milk yield $(\mathrm{kg})$ and BT (min), measuring the milking efficiency in AMS. Handling time is the difference between BT and milking time and sums the time before the milk starts flowing and the time from when the last teat cup was removed to the time the cow leaves the AMS (same definition as Carlström et al., 2016). Milking time was calculated from records on FR by dividing milk yield $(\mathrm{kg})$ in each udder quarter by the average FR for the respective udder quarter. We used the value from the udder quarter with the longest milking time for calculation of HT. Milking time was not further analyzed. Information on FR (measured as average $\mathrm{kg}$ of milk/min of milking time) was available in the milking report. Values on FR in each udder quarter added up to $1 \mathrm{FR}$ record at each milking. Therefore, cows with fewer than 4 milked udder quarters had a lower FR. In addition, milking interval (MI; the time between milking sessions) and milking frequency (MF; the number of milkings per day) were 
analyzed. Information on visits to the milking unit that were unapproved due to short time since the previous milking was also analyzed. This trait (RM) is the daily number of visits for cows in AMS without being milked. The time until a cow again obtains milking permission usually depends on lactation stage and expected milk yield. Restrictions on MI can also be set individually. It is preferred that the animals have few or no RM because RM reduces the milking capacity of the AMS and is therefore described as an undesirable behavior.

Unsuccessful Milkings. The trait called KO is the daily number of milkings with at least 1 teat cup kicked off. This occurs if the teat cup falls out of the gripper or loosens from the teat during attachment or udder milking. The trait was defined as binary ( 0 or 1) per milking and summarized across all milkings per day. A cow with 1 or more $\mathrm{KO}$ in each milking session and with 3 daily milkings would thus be registered as $\mathrm{KO}=3$. The AMS records a teat as not found if the robot arm is unable to detect the teat, resulting in $0 \mathrm{~kg}$ of milk for the specific udder quarter. Teat not found (TNF) was defined as the number of daily milkings in which the milking robot was unable to find at least 1 of the teats for milking. Incomplete milkings was defined as number of daily milkings with a minimum of 1 teat registered as incompletely milked. The expected milk yield for a milking session depends on previous milkings. If the yield was less than $60 \%$ of expectation for a teat, the milking session would be recorded as having an incompletely milked teat.

Traits with Daily Observations. Traits that describe cows' daily milkability and temperament were defined as daily averages of BT, MEF, HT, FR, and MI. The MF and RM were daily sums. To obtain a closer to normal distribution of HT, a constant (1.5) was added before the natural logarithm was calculated and analyzed as an alternative definition of HT (lnHT).

Traits Summarized over Lactations. Due to the low frequency of recorded unsuccessful milkings when defined as a daily record, a second definition of KO, IM, $\mathrm{TNF}$, and RM was analyzed in which they were summarized to 1 observation per lactation. The proportion (p) of milkings with KO, TNF, and IM was calculated with the following formula:

pKO, pTNF, pIM = No. of milkings with KO,

TNF, or IM/Total milkings per lactation.

The following formula was used to calculate pRM:

$\mathrm{pRM}=$ No. of rejected milkings/

Total visits per lactation.

\section{Data Edits}

The data set included a total of 4,907,751 observations, and only Norwegian Red cows were included in the analysis. A record consisted of either a milking or a rejected milking. Additional information such as calving dates and pedigree for all animals was collected from the Norwegian Dairy Herd Recording System. Records from each visit were summarized to 1 record per day for each cow and further edited. Each cow should have a minimum of 10 successive DIM between d 5 and 305 of a parity. For each test day and cow, the number of milkings and rejected milkings was restricted to a maximum of 11 and 30, respectively. Milk yield had to be $\leq 50 \mathrm{~kg}$ in total per milking and $\leq 13 \mathrm{~kg}$ per udder quarter per milking. Average FR and peak FR had a respective maximum of 3 and $4 \mathrm{~kg}$ of milk/min and udder quarter per milking. The time interval between milkings should not be shorter than $5 \mathrm{~min}$, and time variables had to be positive and logical. The BT was restricted to be between 1 and $20 \mathrm{~min}$. The minimum and maximum length of HT was 0.3 and $15 \mathrm{~min}$, respectively. The final data set had a total of 1,012,912 daily observations dated from December 2015 to July 2017 on 4,883 cows and 6,493 lactations in 77 herds.

Summary statistics are given in Table 1. The total number of daily observations varied among traits from 977,522 to $1,012,912$. The mean BT per visit was 7.46 min. Both BT and HT showed large variation. Average MI was $9.91 \mathrm{~h}$; however, a few observations had a large interval from one milking to the next. The maximum MI value of $1,207.8 \mathrm{~h}$ was likely caused by an udder health or milk quality problem resulting in a longer period without recorded milkings in AMS. Average FR was $3.25 \mathrm{~kg}$ of milk/min, whereas milk per minute of $\mathrm{BT}, \mathrm{MEF}$, was on average $1.48 \mathrm{~kg} / \mathrm{min}$. Average MF was 2.63. Average number of daily milkings with $\mathrm{KO}$, IM, and TNF ranged from 0.11 to 0.17 . Traits summarized per lactation (pKO, pTNF, pIM, and pRM) had in total 6,706 observations, and proportion ranged from 0 to 1 (Table 2 ). The mean proportions were generally low, ranging from 0.05 to 0.11 .

For BT, HT, MEF, and FR, the daily average varied over DIM within parity and between parities. The largest difference between first and later lactations was found for MEF, with a difference of $0.3 \mathrm{~kg} / \mathrm{min}$ in the first part of the lactation (Figure 1). Cows in first lactation showed peak MEF around 140 DIM, whereas the peak occurred earlier for older cows in our data. Firstlactation cows showed lower average FR compared with later parities, with a flatter curve through the parity (Figure 2). The pattern of HT through lactation was relatively similar across parities. There was longer HT 
Table 1. Summary statistics for traits with 1 daily record in automatic milking systems

\begin{tabular}{lccccc}
\hline Trait & $\mathrm{n}$ & Mean & $\mathrm{SD}$ & \multirow{2}{*}{ Minimum } & Maximum \\
\hline Box time (min) & $1,012,534$ & 7.46 & 1.96 & 1 & 20 \\
Milking efficiency (kg/min) & $1,012,588$ & 1.48 & 0.44 & 0 & 4 \\
Handling time (min) & $1,007,179$ & 3.14 & 1.13 & 0.3 & 15 \\
Log-transformed handling time (ln) & $1,007,179$ & 1.51 & 0.21 & 0.59 & 2.8 \\
Flow rate (kg/min) & 977,522 & 3.25 & 0.93 & 0 & 8.8 \\
Milking frequency (no.) & $1,012,912$ & 2.63 & 0.80 & 0 & 11 \\
Milking interval (h) & $1,012,092$ & 9.91 & 5.61 & 0.91 & $1,207.8$ \\
Rejected milkings (no.) & $1,012,912$ & 0.5 & 1.55 & 0 & 30 \\
Milkings with kick-off (no.) & $1,012,601$ & 0.17 & 0.52 & 0 & 7 \\
Incomplete milkings (no.) & $1,012,601$ & 0.12 & 0.45 & 0 & 7 \\
Milkings with teat not found (no.) & $1,012,601$ & 0.11 & 0.43 & 0 & 7 \\
\hline
\end{tabular}

early and late in the lactations, except for first parity, which showed a pattern of lower HT toward the end of the lactation (Figure 3).

\section{Statistical Method and Models}

Mixed linear animal models were used for analyzing the traits. Univariate models were used for variance components and heritability estimation of all the traits, and bivariate models were used for estimating genetic correlations. All variance and covariance components were estimated with the DMUAI package in DMU (Madsen and Jensen, 2012) based on the average information restricted maximum likelihood method. Which fixed effects to include in the model were determined using the GLM procedure in SAS version 9.4 (SAS Institute Inc., Cary, NC). Only fixed effects that had a significant effect were included in the final model for genetic analysis.

Model for Traits with Daily Records. Animal models with repeated measurements within lactations were used for traits with daily records. The univariate model was as follows:

$$
\begin{gathered}
\mathrm{y}_{\mathrm{ijklmn}}=\mathrm{CYM}_{\mathrm{i}}+\text { PCAge }_{\mathrm{j}}+\mathrm{DIM}_{\mathrm{k}}+\mathrm{HTD}_{\mathrm{l}} \\
+\mathrm{pe}_{\mathrm{m}}+\mathrm{a}_{\mathrm{m}}+\mathrm{e}_{\mathrm{ijklmn}},
\end{gathered}
$$

where $\mathrm{y}_{\mathrm{ijklmn}}$ is a daily record of BT (min), HT (min), $\operatorname{lnHT}, \mathrm{MEF}(\mathrm{kg} / \mathrm{min}$ of BT), FR ( $\mathrm{kg} / \mathrm{min})$, MI (h), or $\mathrm{MF}$ (number of milkings) for cow $\mathrm{m} ; \mathrm{CYM}_{\mathrm{i}}$ is the fixed effect of calving year and month $\mathrm{i}$; $\mathrm{PCAge}_{\mathrm{j}}$ is the fixed effect of calving age in months within parity $\mathrm{j} ; \mathrm{DIM}_{\mathrm{k}}$ is the fixed effect of DIM k; and $\mathrm{HTD}_{1}$ is the fixed effect of herd-test day 1 . The random effects included were permanent environment $\left(\mathrm{pe}_{\mathrm{m}}\right)$ of cow $\mathrm{m}$ due to repeated observations, pe $\sim N\left(0, \mathbf{I} \sigma_{\mathrm{pe}}^{2}\right)$, where $\mathbf{I}$ is the identity matrix, $\sigma_{\mathrm{pe}}^{2}$ is the permanent environmental variance, and additive genetic effect $\left(\mathrm{a}_{\mathrm{m}}\right)$ of animal $\mathrm{m}$, $\mathrm{a} \sim N\left(0, \mathbf{A} \sigma_{\mathrm{a}}^{2}\right)$, where $\sigma_{\mathrm{a}}^{2}$ is the additive genetic variance and $\mathbf{A}$ is the relationship matrix containing pedigree information 8 generations back for 43,224 animals. The random effect of residual $\left(\mathrm{e}_{\mathrm{ijklmn}}\right)$ of observation $\mathrm{n}$ was assumed to have the following distribution: e $\sim N\left(0, \mathbf{I} \sigma_{\mathrm{e}}^{2}\right)$, where $\sigma_{\mathrm{e}}^{2}$ is the residual variance.

The following model was used for daily number of milkings with KO, IM, TNF, and daily number of RM:

$$
\begin{aligned}
\mathrm{y}_{\mathrm{ijklmno}}= & \text { CYM }_{\mathrm{i}}+\text { PCAge }_{\mathrm{j}}+\text { DIMperiod }_{\mathrm{k}}+\mathrm{HY}_{\mathrm{l}} \\
& +\operatorname{htd}_{\mathrm{m}}+\mathrm{pe}_{\mathrm{n}}+\mathrm{a}_{\mathrm{n}}+\mathrm{e}_{\mathrm{ijklmno}},
\end{aligned}
$$

where $\mathrm{y}_{\mathrm{ijk} k \mathrm{mno}}$ is a daily observation of $\mathrm{KO}, \mathrm{IM}, \mathrm{TNF}$, or RM for cow $n$ with fixed effect of CYM i and PCAge $j$. For these traits, DIM was grouped in periods of $30 \mathrm{~d}(\mathrm{k}$ $=1-10)$, and herd by year $\left(\mathrm{HY}_{\mathrm{l}}\right)$ was included as a fixed effect. The effect of herd-test day $\left(h \mathrm{hd}_{\mathrm{m}}\right)$ was included as random due to low frequency in the subclasses and had the following distribution: htd $\sim N\left(0, \mathbf{I} \sigma_{\text {htd }}^{2}\right)$, where $\mathbf{I}$ is the identity matrix and $\sigma_{h t d}^{2}$ is the herd-test day variance. Other random effects included were as defined in the model for daily records. Some classes of fixed effects were merged to ensure enough observations in each class. For example, CYM (21 classes) were recorded from April 2015 to June 2017, and the size of classes in the tails was small; CYM from April to August 2015 were merged into 1 class, as were CYM from April to June 2017. Animals

Table 2. Summary statistics for proportion of traits (1 observation/ lactation) of first- to ninth-parity cows in automatic milking systems $(\mathrm{n}=6,706)$

\begin{tabular}{lcccc}
\hline Trait $^{1}$ & Mean & SD & Minimum & Maximum \\
\hline pKO & 0.07 & 0.14 & 0 & 1 \\
pIM & 0.05 & 0.09 & 0 & 1 \\
pTNF & 0.05 & 0.10 & 0 & 1 \\
pRM & 0.11 & 0.18 & 0 & 0.88 \\
\hline
\end{tabular}

${ }^{1} \mathrm{pKO}=$ proportion of milkings with kick-off; $\mathrm{pIM}=$ proportion of incomplete milkings; pTNF = proportion of milkings with teat not found; $\mathrm{pRM}=$ proportion of rejected milkings. 


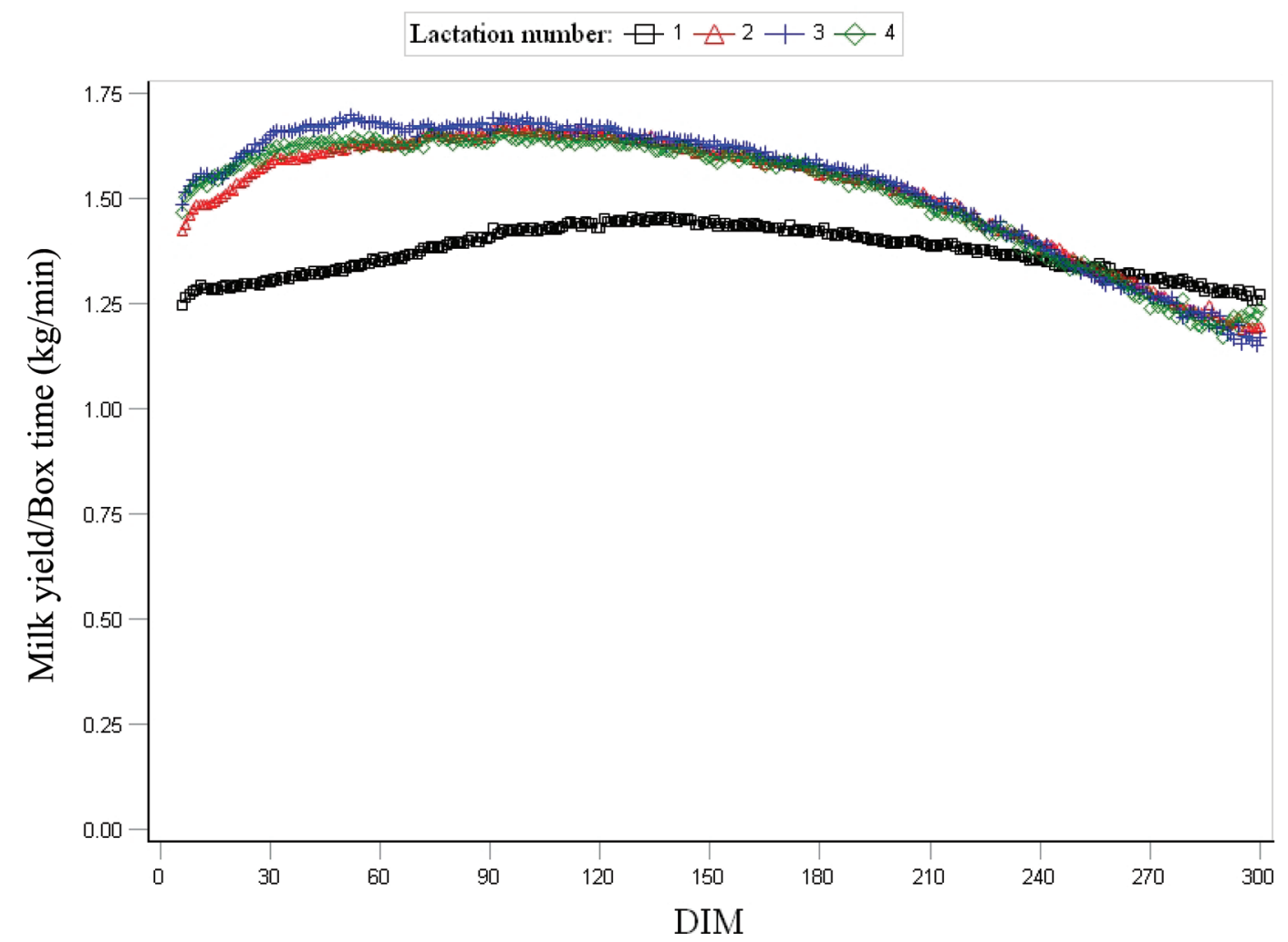

Figure 1. Milking efficiency measured as kilograms of milk per minute of box time in automatic milking systems for dairy cows in first, second, third, and fourth or greater parity.

in first and second lactation were fitted with an effect of parity by calving age (PCAge), whereas cows in later parities only had the effect of lactation number. The effect of parity 5 or later was in 1 class. In first parity, the calving ages $\leq 20$ mo were merged and ages $>32$ mo were merged. In second parity, calving ages $<33$ were in one group and ages $>43$ mo were in another. The total number of classes of PCAge was 30, and there were 27,655 levels of htd and 149 classes of HY.

Model for Traits Summarized over Lactations. For pKO, pIM, pTNF, and pRM, variance components were estimated using the following repeatability model:

$$
\mathrm{y}_{\mathrm{ijklm}}=\mathrm{CYM}_{\mathrm{i}}+\mathrm{PCAge}_{\mathrm{j}}+\mathrm{hy}_{\mathrm{k}}+\mathrm{pe}_{\mathrm{l}}+\mathrm{a}_{\mathrm{l}}+\mathrm{e}_{\mathrm{ijklm}},
$$

where $\mathrm{y}_{\mathrm{ijkl}}$ is an observation of pKO, pIM, pTNF, or $\mathrm{pRM}$ on cow l. For pRM and pKO, the models included fixed effects of CYM i and PCAge j. For pIM and pRM, no fixed effects were included in the models. Due to small subclasses, herd-year (hy) was included as a random effect in the models, with hy $\sim N\left(0, \mathbf{I} \sigma_{\text {hy }}^{2}\right)$, where $\mathbf{I}$ is the identity matrix. Permanent environmental effect (pe) was included due to repeated observations over parities. Other effects were as defined above.
Repeatability and Heritability. Heritability $\left(\mathrm{h}^{2}\right)$ for the traits was defined as

$$
\mathrm{h}^{2}=\frac{\sigma_{\mathrm{a}}^{2}}{\sigma_{\mathrm{a}}^{2}+\sigma_{\mathrm{pe}}^{2}+\sigma_{\mathrm{e}}^{2}},
$$

where $\sigma_{\mathrm{a}}^{2}$ is the additive animal genetic variance, $\sigma_{\mathrm{pe}}^{2}$ is the permanent environment variance, and $\sigma_{\mathrm{e}}^{2}$ is the residual variance.

Repeatability ( $\mathrm{R}$ ) of a trait is the proportion of the total variance explained by the animal, both their additive genetic and permanent environmental effects. The following formula was used to calculate repeatability:

$$
\mathrm{R}=\frac{\sigma_{\mathrm{a}}^{2}+\sigma_{\mathrm{pe}}^{2}}{\sigma_{\mathrm{a}}^{2}+\sigma_{\mathrm{pe}}^{2}+\sigma_{\mathrm{e}}^{2}} .
$$

\section{Genetic Correlations}

A set of bivariate models was used for estimating the genetic correlations among traits. Genetic correlations were estimated only within the groups of traits defined 
as daily or as a proportion. The following assumptions were made for distribution of random effects:

$$
\begin{gathered}
{\left[\begin{array}{l}
\mathrm{a}_{1} \\
\mathrm{a}_{2}
\end{array}\right] \sim N\left[\left(\begin{array}{l}
0 \\
0
\end{array}\right), \mathbf{A} \otimes\left(\begin{array}{cc}
\sigma_{\mathrm{a}_{1}}^{2} & \sigma_{\mathrm{a}_{1} \mathrm{a}_{2}} \\
\sigma_{\mathrm{a}_{1} \mathrm{a}_{2}} & \sigma_{\mathrm{a}_{2}}^{2}
\end{array}\right)\right],} \\
{\left[\begin{array}{l}
\mathrm{pe}_{1} \\
\mathrm{pe}_{2}
\end{array}\right] \sim N\left[\left(\begin{array}{l}
0 \\
0
\end{array}\right), \mathbf{I} \otimes\left(\begin{array}{cc}
\sigma_{\mathrm{pe}_{1}}^{2} & \sigma_{\mathrm{pe}_{1} \mathrm{pe}_{2}} \\
\sigma_{\mathrm{pe}_{1} \mathrm{pe}_{2}} & \sigma_{\mathrm{pe}_{2}}^{2}
\end{array}\right)\right],} \\
{\left[\begin{array}{l}
\mathrm{htd}_{1} \\
\mathrm{htd}_{2}
\end{array}\right] \sim N\left[\left(\begin{array}{l}
0 \\
0
\end{array}\right), \mathbf{I} \otimes\left(\begin{array}{cc}
\sigma_{\mathrm{htd}_{1}}^{2} & \sigma_{\mathrm{htd}_{1} \mathrm{htd}_{2}} \\
\sigma_{\mathrm{htd}_{1} \mathrm{htd}_{2}} & \sigma_{\mathrm{htd}_{2}}^{2}
\end{array}\right)\right],}
\end{gathered}
$$

and

$$
\left[\begin{array}{c}
\mathrm{e}_{1} \\
\mathrm{e}_{2}
\end{array}\right] \sim N\left[\left(\begin{array}{l}
0 \\
0
\end{array}\right), \mathbf{I} \otimes\left(\begin{array}{cc}
\sigma_{\mathrm{e}_{1}}^{2} & \sigma_{\mathrm{e}_{1} \mathrm{e}_{2}} \\
\sigma_{\mathrm{e}_{1} \mathrm{e}_{2}} & \sigma_{\mathrm{e}_{2}}^{2}
\end{array}\right)\right],
$$

where $\sigma_{\mathrm{a}_{1}}^{2}$ and $\sigma_{\mathrm{a}_{2}}^{2}$ are the additive genetic variance for the 2 traits, $\sigma_{\mathrm{a}_{1} \mathrm{a}_{2}}$ is the additive genetic covariance be- tween the 2 traits, $\sigma_{\mathrm{pe}_{1}}^{2}$ and $\sigma_{\mathrm{pe}_{2}}^{2}$ is the permanent environmental variance for repeated observations within lactation and between parities for daily and proportion traits, $\sigma_{\mathrm{pe}_{1} \mathrm{pe}_{2}}$ is the permanent environmental covariance, $\sigma_{\text {htd }_{1}}^{2}$ and $\sigma_{\text {htd }_{2}}^{2}$ is herd-test day variance, and $\sigma_{\mathrm{htd}_{1} \mathrm{htd}_{2}}$ is the herd-test day covariance between the 2 traits. The residual variance for the 2 traits is $\sigma_{\mathrm{e}_{1}}^{2}$ and $\sigma_{\mathrm{e}_{2}}^{2}$, whereas $\sigma_{\mathrm{e}_{1} \mathrm{e}_{2}}$ is the residual covariance.

\section{RESULTS}

Estimates of variance components, heritabilities, and repeatabilities for traits with daily records are given in Table 3. The highest heritability was found for FR (0.48), together with BT and MEF (0.27 and 0.22). All traits except TNF had a genetic component significantly different from 0 , and TNF was the only trait not heritable when defined as daily records. Heritability was very low (0.01-0.02) for IM, RM, and MI, whereas $\mathrm{HT}$, MF, and KO had slightly higher heritability (0.05-0.06). Repeatabilities varied from 0.13 to 0.86 , and estimates for milkability traits ranged from 0.66 to 0.86 . For traits related to temperament or behavior,

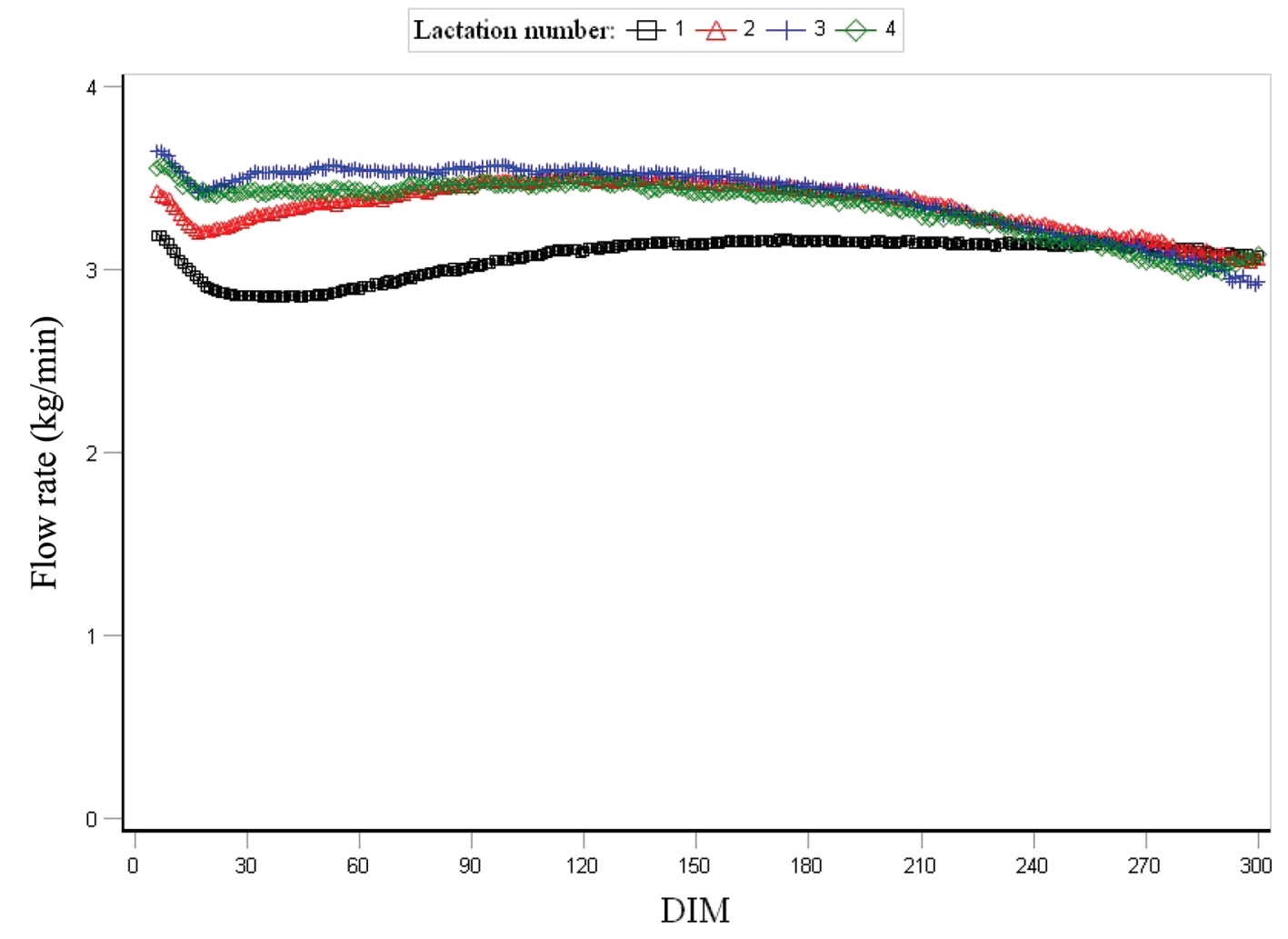

Figure 2. Daily average flow rate ( $\mathrm{kg}$ of milk/min of milking time) in automatic milking systems for dairy cows in first, second, third, and fourth or greater parity. 
Table 3. Variance components, repeatability, and heritability (SE in parentheses) for traits with daily records in automatic milking systems

\begin{tabular}{|c|c|c|c|c|c|c|c|}
\hline Trait $^{1}$ & \multicolumn{7}{|c|}{ Variance component $^{2}$} \\
\hline $\operatorname{lnHT}$ & $0.002(<0.001)$ & $0.02(<0.01)$ & NI & $0.02(<0.001)$ & 0.04 & 0.50 & $0.07(0.02)$ \\
\hline BT (min) & $0.96(0.11)$ & $1.47(0.09)$ & NI & $1.16(<0.01)$ & 3.59 & 0.68 & $0.27(0.03)$ \\
\hline MEF $(\mathrm{kg} / \mathrm{min}$ of $\mathrm{BT})$ & $0.04(<0.01)$ & $0.07(<0.01)$ & NI & $0.06(<0.001)$ & 0.17 & 0.66 & $0.22(0.03)$ \\
\hline $\mathrm{FR}(\mathrm{kg} / \mathrm{min})$ & $0.40(0.04)$ & $0.33(0.03)$ & NI & $0.12(<0.001)$ & 0.84 & 0.86 & $0.48(0.04)$ \\
\hline RM (no.) & $0.02(0.01)$ & $0.50(0.01)$ & $0.30(0.03)$ & $0.81(0.001)$ & 1.33 & 0.39 & $0.02(<0.01)$ \\
\hline KO (no.) & $0.02(0.004)$ & $0.11(<0.01)$ & $0.001(<0.001)$ & $0.17(<0.001)$ & 0.30 & 0.43 & $0.06(0.01)$ \\
\hline IM (no.) & $0.002(0.001)$ & $0.05(0.001)$ & $0.002(<0.001)$ & $0.16(0.002)$ & 0.21 & 0.25 & $0.01(0.005)$ \\
\hline TNF (no.) & $0.0005(0.001)$ & $0.06(0.002)$ & $0.002(<0.001)$ & $0.13(0.002)$ & 0.20 & 0.32 & $0.002(0.004)$ \\
\hline
\end{tabular}

${ }^{1} \mathrm{HT}=$ handling time; $\operatorname{lnHT}=\log$-transformed $\mathrm{HT} ; \mathrm{BT}=$ box time; MEF = milking efficiency; $\mathrm{FR}=$ flow rate; MF = milking frequency; MI $=$ milking interval; $\mathrm{RM}=$ rejected milkings; $\mathrm{KO}=$ kick-offs; $\mathrm{IM}=$ incomplete milkings; $\mathrm{TNF}=$ teat not found.

${ }^{2} \sigma_{\mathrm{a}}^{2}=$ additive genetic variance; $\sigma_{\mathrm{pe}}^{2}=$ permanent environmental variance; $\sigma_{\mathrm{htd}}^{2}=$ herd-test day variance; $\sigma_{\mathrm{e}}^{2}=$ residual variance; $\sigma_{\mathrm{p}}^{2}=$ phenotypic variance $\left(\sigma_{\mathrm{a}}^{2}+\sigma_{\mathrm{pe}}^{2}+\sigma_{\mathrm{e}}^{2}\right) ; \mathrm{R}=$ repeatability, $\mathrm{h}^{2}=$ heritability.

${ }^{3}$ Not included in the model.

HT and KO had the highest repeatability (0.48 and $0.43)$, together with RM (0.39). Low repeatability and heritability were estimated for MI.

Results on pKO, pIM, pTNF, and pRM analyzed as proportion of occurrence within lactations are given in
Table 4. Variance component estimates were significantly different from 0 for all traits, with heritabilities varying from 0.05 to 0.14 . Heritability was lowest for pRM and highest for pIM. Proportion of milkings with $\mathrm{KO}(\mathrm{pKO})$ showed the highest repeatability (0.72),

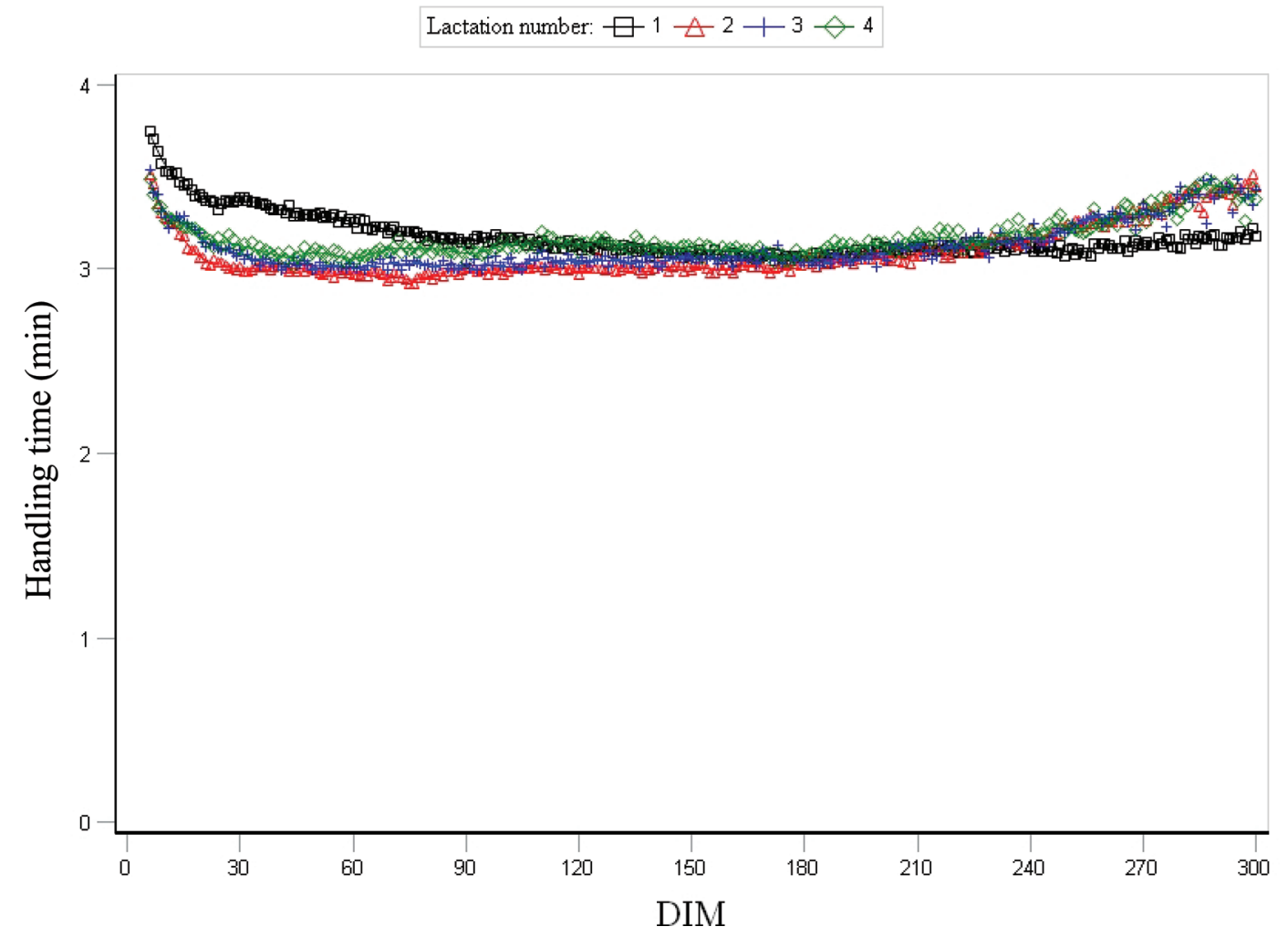

Figure 3. Daily average handling time ( $\mathrm{min})$ measured in automatic milking systems for dairy cows in first, second, third, and fourth or greater parity. 
whereas the other traits had relatively low repeatabilities ranging from 0.29 to 0.36 .

Estimated genetic correlations between temperament and milkability traits with daily records are given in Table 5. The correlations were intermediate to strong and favorable among the continuous traits MEF, HT, FR, and BT. They were lower than -0.50 and larger than 0.53. The strong correlation between FR and MEF (0.98) confirmed that these are genetically the same traits. A negative and strong correlation of -0.92 between FR and BT means that selection for higher FR results in shorter BT. The negative moderate correlation HT showed with MEF and FR $(-0.58$ and -0.50 , respectively) was favorable because shorter HT is genetically associated with higher MEF and FR.

Both MF and MI showed a weak or nonexistent genetic relationship with the continuous traits (BT, HT, $\mathrm{MEF}$, and FR) but were strongly interrelated (-0.99). The genetic correlation of 0.98 between $\mathrm{KO}$ and IM means that they are the same trait genetically, and their genetic correlations with other traits are also in the same range. Among traits associated with unsuccessful milkings, IM and KO had the strongest genetic correlations with milkability traits. These correlations were moderate and in expected directions. The stronger genetic correlation between $\mathrm{KO}$ and IM when measured as daily observations compared with pKO and pIM may be related to the definition of the traits. When defined as proportions, total number of milkings are accounted for, resulting in larger variation between the traits and a more continuous scale. Positive correlations ranging from 0.31 to 0.53 for $\mathrm{KO}$ and IM with $\mathrm{BT}$ and $\mathrm{HT}$ means that increased number of milkings with $\mathrm{KO}$ and incompletely milked teats will increase occupation time and HT in the AMS. The negative genetic correlation between $\mathrm{KO}$ and IM with MEF and FR suggests that increased KO and IM will reduce yield per minute. The strong and negative genetic correlation between IM and MI (-0.7) suggests reduced milk yield in each session with shorter MI; this leads to IM according to the definition. For TNF, no significant genetic correlations with other traits when defined as daily number of milkings were found, as standard errors were larger than estimated correlations or analysis did not converge.

Five out of six of the genetic correlations estimated among pIM, pTNF, pKO, and pRM were significantly different from zero (Table 6). The strongest genetic correlation was found between pIM and pTNF (0.99 $\pm 0.02)$. This indicates that the 2 traits are genetically the same. Moderate genetic correlations were estimated between pIM and pKO (0.30) and between pIM and pRM (0.36). Further, a moderate genetic correlation between pTNF and pRM was estimated to be 0.46 but with a relatively large standard error (0.2).

\section{DISCUSSION}

\section{Heritability and Repeatability}

Several of the novel phenotypes investigated associated with milkability, milking temperament, and efficiency in AMS showed genetic variation. The low heritability of MF (0.05) was in line with estimates (0.02-0.07) found for Swedish cows (Carlström et al., 2013). Nixon et al. (2009) estimated heritabilities for 24-h milking frequency ranging from 0.02 to 0.08 for primiparous Holstein cows. König et al. (2006) reported slightly higher heritability for MF at 3 different test days $(0.16,0.19,0.22)$ when a linear regression of milking frequency on milk yield was included in the model. Heritability for MI of 0.02 is very low compared with the results of Carlström et al. (2013) in the range of 0.09 to 0.26 . This may be due to less restrictive data edits than those applied by Carlström et al. (2013). The relevance of MF for breeding is related to robot capacity. Both too few and too many daily milkings are

Table 4. Variance components, repeatability, and heritability for proportion traits (1 observation/lactation; SE in parentheses) in automatic milking systems

Variance component ${ }^{2}$

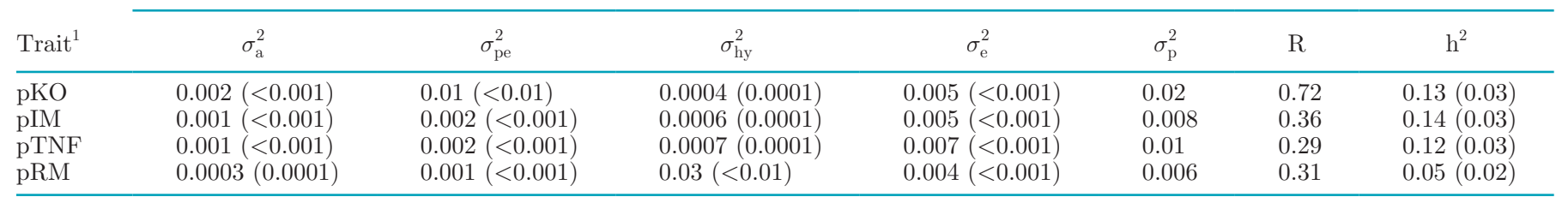

${ }^{1} \mathrm{pKO}=$ proportion of milkings with kick-off; pIM = proportion of incomplete milkings; pTNF $=$ proportion of milkings with teat not found; $\mathrm{pRM}=$ proportion of rejected milkings.

${ }^{2} \sigma_{\mathrm{a}}^{2}=$ additive genetic variance; $\sigma_{\mathrm{pe}}^{2}=$ permanent environmental variance; $\sigma_{\mathrm{hy}}^{2}=$ herd-year variance; $\sigma_{\mathrm{e}}^{2}=$ residual variance; $\sigma_{\mathrm{p}}^{2}=$ phenotypic variance $\left(\sigma_{\mathrm{a}}^{2}+\sigma_{\mathrm{pe}}^{2}+\sigma_{\mathrm{e}}^{2}\right) ; \mathrm{R}=$ repeatability, $\mathrm{h}^{2}=$ heritability. 
undesirable: low MF increases labor related to fetching cows, whereas MF that is too large reduces available milking capacity for each cow.

Moderate to high heritability for BT (0.27) was in the same range as the only comparable results reported by Carlström et al. (2013). This trait relates directly to robot capacity because short BT improves animal flow. Also, MEF relates to milking capacity and showed a heritability of 0.22 . This trait has been sparsely investigated, but Bakke and Heringstad (2015) found a heritability of 0.29 in a study based on data from 46 commercial herds with Norwegian Red cows. Vosman et al. (2018) estimated the heritability of kilograms of milk per minute of BT to be 0.33 and 0.29 , respectively, for 2 definitions of milking efficiency (EFF1, EFF2). In the work by Vosman et al. (2018), the EFF1 definition corresponds to MEF, but EFF2 is kilograms of milk divided by BT and includes values from previous IM. Løvendahl et al. (2014) found higher heritabilities for milking efficiency at different stages of first lactation (0.4-0.5). They defined milking efficiency as a ratio of total daily BT to energy corrected yield, almost identical to MEF in the current study. Løvendahl et al. (2014) also defined residual milking BT as BT adjusted for ECM yield at every visit. This definition showed lower heritability compared with milking efficiency in kilograms per minute. They used average values of 10 stages through first lactation only, and this may be a reason for their relatively higher heritability estimates.

The highest heritability in the current study was estimated for FR (0.48), and the repeatability of 0.86 confirmed that milking robots measure milking speed highly accurately. Carlström et al. (2013) estimated heritability of average FR in Swedish Red cows to be 0.37 in first parity and 0.48 in second and third parity. Both heritability and repeatability of FR in the Swedish study were comparable with the current study, where FR was analyzed across all parities. A heritability of FR close to 0.50 was reported for Holsteins by Pretto et al. (2014). Gäde et al. (2006) found that heritabilities of average and maximum FR were 0.55 when based on daily records. They also found milking time to have a

Table 6. Genetic correlations between proportion traits in automatic milking systems (1 observation/lactation; SE in parentheses) ${ }^{1}$

\begin{tabular}{lrll}
\hline Trait & \multicolumn{1}{c}{ pKO } & pTNF & pRM \\
\hline pTNF & $0.20(0.17)$ & & \\
pRM & $-0.20(0.22)$ & $0.46(0.2)$ & \\
pIM & $0.30(0.14)$ & $0.99(0.02)$ & $0.36(0.19)$ \\
\hline
\end{tabular}

${ }^{1} \mathrm{pKO}=$ proportion of milkings with kick-offs; $\mathrm{pTNF}=$ proportion of milkings with teat not found; $\mathrm{pRM}=$ proportion of rejected milkings; $\mathrm{pIM}=$ proportion of incomplete milkings. 
high heritability (0.39) and estimated strong correlations between these traits, ranging from -0.89 to 0.98 .

Milking speed of first-lactation Norwegian Red cows has been scored subjectively on a 3 -point scale by farmers and is currently used in the genetic evaluation of temperament. Heritability estimates of milking speed scored subjectively by either farmers or classifiers were in the range of 0.16 to 0.25 for different breeds (Luttinen and Juga, 1997; Rupp and Boichard, 1999; Ilahi and Kadarmideen, 2004). Average FR based on objective measurements by milk meters have higher heritabilities, from 0.27 to 0.54 (Ilahi and Kadarmideen, 2004; Gray et al., 2011). Carlström et al. (2014) showed that heritability decreased when fewer days of data were included, but estimates were still relatively large for milking speed measured as average FR. This implies that few days with data from AMS may still be feasible as information for genetic evaluation of milkability. Pretto et al. (2014) reported a strong and positive genetic correlation (0.92) between average FR in AMS and FR in milking parlors. Carlström et al. (2014) found even higher correlations between FR in AMS and FR registered in milking parlors for Swedish Red and Holstein cows (0.98 and 0.97, respectively). Strong genetic correlations between FR in AMS across parities $(>0.9)$ were also found by Carlström et al. (2014).

Transformation of HT to lnHT reduced skewness and increased heritability from 0.05 to 0.07 . The trait is a relevant source of information on cow temperament and time usage before attachment of milking equipment and after teat cups are removed. Carlström et al. (2013) used a similar definition of HT and found similar estimates of heritability of 0.05 and 0.15 for first- to third-lactation Holstein and Swedish Red cows, respectively. Negative HT values were deleted in the data edit. They may arise from measurement errors in FR, leading to calculated milking time being longer than actual BT. Time from start of milking until milk flow stops when the last teat cup is removed may be a better measurement of milking time to prevent illogical HT. Almost the same definition of milking time was used by Carlström et al. (2013), but they added a constant of $30 \mathrm{~s}$ to the attachment time of each fore udder quarter before keeping the record with the largest milking time.

In a recent study, Stephansen et al. (2018) estimated heritability of connection time of attachment of teat cups and number of attachments per udder quarter as a measure of milking temperament in AMS. They found relatively high heritabilities $(0.36$ and 0.26 , respectively). They also reported significant favorable correlations between farmer-assessed temperament and connection time of teat cups in minutes and number of attachments of -0.29 and -0.37 , respectively. In the current study, $\mathrm{KO}$ was investigated as an indicator of milking temperament in AMS. Kick-offs defined as teat cup attachment failures (AtF) in AMS were studied for Swedish Holstein cows by Rinell et al. (2014). They found heritability estimates of 0.31 and 0.06 for proportion and number of AtF, respectively. The KO in the present study showed heritability similar to AtF, whereas it was lower for pKO. This may be due to larger means for proportion of $\mathrm{AtF}(30 \%)$ than for $\mathrm{pKO}$ (7\%) in this study. Carlström et al. (2016) investigated proportion of AtF in first-parity Swedish Red cattle and found mean percentage of AtF to be $22.6 \%$ and a heritability of 0.21 . The current study included later lactations as well, and animals with poor milking temperament were probably culled during first lactation. This may explain the lower percentage of $\mathrm{KO}$ when later parities are included. For pIM, heritability was larger than that found in Carlström et al. (2016), whereas the mean was almost equal. Bakke and Heringstad (2015) also found a smaller heritability for pIM (0.08).

The trait TNF had a heritability of 0.12 when defined as pTNF, but with no significant genetic variation as daily observations. Rejected milking was the only trait describing behavior between milkings in AMS, and this study appears to be the first attempt to estimate genetic parameters of such a trait. This makes $\mathrm{RM}$ an interesting trait considering behavior unrelated to milking. The heritability of RM was, however, low for both definitions; instead, there were considerable nongenetic animal effects and herd $x$ year differences. As far as the authors know, there are no other studies with which to compare the results for TNF and RM.

\section{Genetic Correlations}

Among the traits recorded on a continuous scale (BT, MEF, HT, FR), genetic correlations were relatively strong as expected, partly because these traits overlap each other by definition. To describe AMS-efficient cows, MEF was analyzed because it is a ratio trait considering both yield and occupation time. The strong correlation of 0.98 between FR and MEF indicates that yield per minute of milking time and per minute of BT are genetically the same trait. With its higher heritability and repeatability, FR has the best potential for utilization in genetic evaluation and can substitute for today's subjective scoring of milking speed.

The strong negative and favorable correlation of -0.92 between FR and BT means that faster FR gives shorter occupation time in the AMS and is in agreement with Carlström et al. (2014). They concluded that BT is an interesting trait explaining efficiency in AMS and has a larger effect on milking capacity of the robot compared with average FR and milking time 
(Carlström et al., 2014, 2016). Occupation time is less important than FR in nonrobotic milking systems because milkers can influence individual occupation time in the milking unit, and milking efficiency is mostly dependent on cows' genetic ability to milk fast. Genetic correlations between FR and both $\operatorname{lnHT}$ and HT $(-0.50$ and -0.59 , respectively) are desirable in terms of less preparation time before and after milking if selection is for increased FR. Another desirable relationship that makes FR interesting for breeding was the correlation suggesting that fewer $\mathrm{KO}$ and IM are associated with larger FR (-0.4).

A favorable and intermediate genetic correlation between milkability measured as MEF and KO in the current study was in agreement with Bakke and Heringstad (2015), who estimated the genetic correlation between pKO and milking speed scored subjectively by farmers to be 0.27 . Contradictory to our results, they found a positive correlation because of inverse scale for the subjective evaluated milking speed. Genetic correlations from both studies therefore suggest that a slow-milking cow also has a tendency for more KO. Bakke and Heringstad (2015) also found a genetic correlation of -0.22 between farmer-assessed temperament and MEF, again a favorable correlation because bad temperament is scored with a larger number. Genetic correlations between farmer-assessed temperament and KO in AMS were estimated to be -0.44 and -0.71 for Holsteins and Swedish Reds, respectively, in a study by Carlström et al. (2016). An intermediate and favorable correlation of 0.54 was also found in Bakke and Heringstad (2015), with a positive correlation due to opposite temperament scale.

The study by Carlström et al. (2016) showed the correlations between HT and farmer-assessed temperament in Swedish Reds and Holsteins $(-0.20$ and -0.29 , respectively) to be lower than the correlation between temperament and KO. The correlation with farmerassessed temperament is valuable for confirming the feasibility of the new traits as a measure of temperament already included in today's breeding program.

\section{Data and Statistical Model}

The current study was a first attempt to estimate genetic parameters of traits that can be defined from phenotypes that can be routinely uploaded from AMS and used for genetic evaluations of temperament and milkability of Norwegian Red dairy cattle. Despite a relatively small data set of around 4,000 cows, estimates were accurate and demonstrate the value of AMS records. The mixed linear animal model with repeated measures per cow was chosen for being a robust model. In addition, this model uses day-to-day information captured by AMS. More advanced models, such as random regression models, could have been used. However, Carlström et al. (2014) showed that the advantages of random regression models were small for $\mathrm{FR}, \mathrm{BT}$, and milking time in AMS. For the traits with daily records, HTD was included as a fixed effect because number of daily observations was larger than 40 and the traits were continuous with sufficient variation within each contemporary group. For the categorical traits with daily observations (KO, IM, TNF, and RM), we defined herd-test day as a random effect due to low frequency of the traits in each subclass. The repeated observations for 1 cow could be both within and across lactations. It is arguably a simplification to assume constant variance within and over different lactations, and an alternative would be to treat parities as different traits with larger data material.

\section{Interpretation of Results}

Milkability. It is possible to combine several milkability and temperament traits in a future genetic evaluation of Norwegian Reds because both categories of traits are important in automatic milking. Previous studies show that BT, FR, HT, and pKO are correlated with subjectively scored milkability and temperament in traditional milking systems. The most promising milkability traits are FR and BT. A heritable alternative explaining milking efficiency in AMS is MEF, which is a ratio trait. This create uncertainty about responses in numerator and denominator. Following Zetouni et al. (2017), a multitrait selection index was proposed as more effective than selecting for a ratio trait. Therefore, selection of yield and BT separately may be a better solution. Initial analysis revealed a weak correlation between MEF and daily milk yield $(0.15 \pm 0.12)$ but a stronger correlation between BT and MEF (-0.87). As a result of the negative genetic correlation, selecting for high MEF will reduce BT at each milking.

Restrictions set by the milking system or manually by the farmer decide how often the cow can be milked, and environmental factors such as social rank and cows per robot have a significant effect on MI and MF. Feeding strategies will also affect the milking frequency in each herd (König et al., 2006). Average MF was 2.63 milkings per day in agreement with Nixon et al. (2009) and Carlström et al. (2013) but lower than 2.7 to 3.05 found by König et al. (2006). We found low heritabilities and weak correlations with other traits for MI and MF, but they were strongly correlated with each other, being 2 definitions of the same feature. However, MF and MI may express characteristics that are important for milking efficiency. 
Temperament Traits in AMS. This study supports pKO as the most promising automatically recorded measure of milking temperament in AMS (Rinell et al., 2014; Bakke and Heringstad, 2015; Carlström et al., 2016). In addition, HT covers other aspects of milking behavior in AMS. Long HT may be caused by a challenging temper or udder conformation. Genetic correlations with pKO and pIM were not estimated, but strong correlations of 0.56 to 0.89 were found by Carlström et al. (2016). They also found a correlation of -0.29 to subjectively scored temperament for Swedish Reds.

Cows with unfavorable udder conformation are likely to also show a large pKO, pIM, and pTNF because teat cups may be improperly attached, fall off, or not be attached at all. Genetic correlation to udder conformation would therefore call for further studies. Important udder conformation traits may also be based on teat coordinate data from AMS (Byskov et al., 2012; Carlström et al., 2016; Poppe et al., 2019). Heritabilities of pKO, pIM, and pTNF (0.12-0.14) are sufficient to obtain genetic progress if properly weighted in a selection scheme, and the genetic correlation shows that pIM and pTNF must be regarded as identical traits. Possible reasons for low heritability of pRM can be restrictions on daily number of visits (forced traffic). This information was not available, so herds practicing both free and forced traffic entered the analysis.

\section{Correlated Traits}

Short BT and HT and fast FR are desirable for efficient and fast milking in AMS. On the other hand, it may not be desirable with premature letdown of milk. Milking speed and FR are optimum traits where milking speeds that are both too fast and too slow correlate with poorer udder health. Unfavorable genetic correlations have been reported between increased SCC, leakage, and milking speed (Luttinen and Juga, 1997), and this relationship should be considered when selecting for a milking-efficient dairy cow.

\section{CONCLUSIONS}

The current study revealed promising genetic parameters for new traits describing milking efficiency and milking temperament in AMS. High heritabilities and genetic variation makes many of the milkability and temperament traits investigated useful for routine genetic evaluation. High repeatability for the continuous traits shows that only few observations are needed during the lactation to get substantial information for breeding purposes. Many traits will be beneficial in other milking systems as well. Our results showed BT,
FR, pKO, and HT to be the most promising traits for describing and improving milkability and temperament in AMS systems.

\section{ACKNOWLEDGMENTS}

The authors gratefully thank all Norwegian farmers for sharing their data for this study. Further, we thank Ingebret Risa at DeLaval Norway for useful information about milking reports. We also thank Erik Brodshaug at Tine SA (Ås, Norway) and Morten Svendsen at Geno Breeding and AI Association (Hamar, Norway). The project "New approaches for management and breeding of dairy cows in automatic milking systems" (project no. 4206000072) provided necessary funding for this study.

\section{REFERENCES}

Bakke, K. A., and B. Heringstad. 2015. Data from automatic milking systems used in genetic evaluations of temperament and milkability. Page 287 in Proc. 66th Annual Meeting of the European Association for Animal Production, Warsaw, Poland. Wageningen Academic Publishers, Wageningen, the Netherlands.

Byskov, K., L. H. Buch, and G. P. Aamand. 2012. Possibilities of implementing measures from automatic milking systems in routine evaluations of udder conformation and milking speed. Interbull Bull. 46:28-32.

Carlström, C., G. Pettersson, K. Johansson, E. Strandberg, H. Stålhammar, and J. Philipsson. 2013. Feasibility of using automatic milking system data from commercial herds for genetic analysis of milkability. J. Dairy Sci. 96:5324-5332. https://doi.org/10.3168/ jds.2012-6221.

Carlström, C., E. Strandberg, K. Johansson, G. Pettersson, H. Stålhammar, and J. Philipsson. 2014. Genetic evaluation of in-line recorded milkability from milking parlors and automatic milking systems. J. Dairy Sci. 97:497-506. https://doi.org/10.3168/jds .2013-6948.

Carlström, C., E. Strandberg, G. Pettersson, K. Johansson, H. Stålhammar, and J. Philipsson. 2016. Genetic associations of teat cup attachment failures, incomplete milkings, and handling time in automatic milking systems with milkability, temperament, and udder conformation. Acta Agric. Scand. A Anim. Sci. 66:75-83.

Gäde, S., E. Stamer, W. Junge, and E. Kalm. 2006. Estimates of genetic parameters for milkability from automatic milking. Livest. Sci. 104:135-146. https://doi.org/10.1016/j.livsci.2006.04.003.

Gray, K. A., F. Vacirca, A. Bagnato, A. B. Samoré, A. Rossoni, and C. Maltecca. 2011. Genetic evaluations for measures of the milkflow curve in the Italian Brown Swiss population. J. Dairy Sci. 94:960-970.

Ilahi, H., and H. N. Kadarmideen. 2004. Bayesian segregation analysis of milk flow in Swiss dairy cattle using Gibbs sampling. Genet. Selection Evol. 36:563-576.

König, S., F. Köhn, K. Kuwan, H. Simianer, and M. Gauly. 2006. Use of repeated measures analysis for evaluation of genetic background of dairy cattle behavior in automatic milking systems. J. Dairy Sci. 89:3636-3644.

Løvendahl, P., J. Lassen, and M. G. G. Chagunda. 2014. Milking efficiency - A milkability trait for automatically milked cows. Page 140 in Proc. 10th World Congress on Genetics Applied to Livestock Production, Vancouver, BC, Canada. WCGALP Digital Archive, http://www.wcgalp.org/.

Luttinen, A., and J. Juga. 1997. Genetic relationships between milk yield, somatic cell count, mastitis, milkability and leakage in Finnish dairy cattle population. Interbull Bull. 15:78-83. 
Madsen, P., and J. Jensen. 2012. DMU, a package for analysing multivariate mixed models. Release 5.1, version 6. Faculty Agricultural Sciences (DJF), Department of Genetics and Biotechnology, University of Aarhus, Tjele, Denmark.

Nixon, M., J. Bohmanova, J. Jamrozik, L. R. Schaeffer, K. Hand, and F. Miglior. 2009. Genetic parameters of milking frequency and milk production traits in Canadian Holsteins milked by an automated milking system. J. Dairy Sci. 92:3422-3430. https://doi .org/10.3168/jds.2008-1689.

Poppe, M., H. A. Mulder, B. J. Ducro, and G. de Jong. 2019. Genetic analysis of udder conformation traits derived from automatic milking system recording in dairy cows. J. Dairy Sci. 102:1386-1396.

Pretto, D., A. Tänavots, H. Kiiman, E. Pärna, H. Viinalass, and T Kaart. 2014. Genetic parameters of average milk flow recorded electronically from milking parlours and automatic milking systems in Estonian Holstein dairy cows. Page 616 in Proc. 10th World Congress of Genetics Applied to Livestock Production, Vancouver, BC, Canada. WCGALP Digital Archive, http://www .wcgalp.org/.

Rinell, E., C. Carlström, B. Heringstad, and E. Strandberg. 2014. Genetic associations between behavior traits recorded by automatic milking systems and temperament of Swedish Holsteins. Page 828 in Proc. 10th World Congress on Genetics Applied to Livestock Production, Vancouver, BC, Canada. WCGALP Digital Archive, http://www.wcgalp.org/.

Rupp, R., and D. Boichard. 1999. Genetic parameters for clinical mastitis, somatic cell score, production, udder type traits, and milking ease in first lactation Holsteins. J. Dairy Sci. 82:2198-2204.

Stephansen, R. S., A. Fogh, and E. Norberg. 2018. Genetic parameters for handling and milking temperament in Danish first-parity Holstein cows. J. Dairy Sci. 101:11033-11039.

Tine. 2017. Statistikksamling fra ku- og geitekontrollen 2017. Accessed Jan. 15, 2019. (In Norwegian with tables in English.) https:/ medlem.tine.no/aktuelt/nyheter/hk-statistikker/statistikksamling $-2017$.

Vosman, J., M. Poppe, H. Mulder, A. Assen, B. Ducro, A. Gerrits, C. Vesseur, J. H. Boes, H. Eding, and G. D. Jong. 2018. Automatic milking system, a source for novel phenotypes as base for new genetic selection tools. Page 286 in Proc. 11th World Congress on Genetics Applied to Livestock Production, Auckland, New Zealand. WCGALP Digital Archive, http://www.wcgalp.org/.

Zetouni, L., M. Henryon, M. Kargo, and J. Lassen. 2017. Direct multitrait selection realizes the highest genetic response for ratio traits. J. Anim. Sci. 95:1921-1925. 